\title{
UM CONFLITO DE CONHECIMENTO: INDIVÍDUO, INIMIZADE E FORÇA NO PENSAMENTO JURÍDICO- POLÍTICO DE HANS KELSEN E CARL SCHMITT
}

\author{
A CONFLICT OF KNOWLEDGE: INDIVIDUAL, ENEMY AND \\ STRENGTH IN THE POLITICAL-LEGAL THOUGHT OF HANS \\ KELSEN AND CARL SCHMITT
}

\author{
Diego Antonio Perini Milão* \\ Andityas Soares de Moura Costa Matos
}

\begin{abstract}
SUMÁRIO: Introdução. 2. Teoria da Jurisdição Constitucional Vs Teoria do Poder Constitucional. 3. Norma Hipotética Fundamental Vs Conceito de Inimigo. 4. Substância Vs Função [Conclusões]. Referências.
\end{abstract}

RESUMO: Carl Schmitt tem Hans Kelsen como um dos seus principais adversários teóricos, principalmente devido ao intuito de Kelsen em desvincular a política do campo da ciência jurídica, defendendo uma concepção unitária de Direito e Estado, identificando-os, ao contrário de Schmitt que concebe uma visão dualista entre Estado e Direito, o que possibilitaria a suspensão do último pelo Soberano para atender ao chamado "interesse público", hipótese veementemente negada por Kelsen. Juntamente com Rudolf Smend e Hermann Heller, Schmitt e Kelsen compunham o chamado "quarteto weimariano", em um período de "vácuo" entre as duas Guerras Mundiais. Não por acaso, o conceito de força exerce uma importância central tanto na obra do mestre da escola de Viena, como na do jurista da "exceção", compondo, assim, o objeto deste artigo: analisar e comparar a questão da violência e a problemática da anomia como fundantes do Direito e do Estado no pensamento desses dois grandes personagens do século XX. Há uma diferença essencial entre Schmitt e Kelsen quanto à extensão do elemento força como fundante do ordenamento jurídico ou da ordem política, limite esse determinado pela idéia de anomia e pela interpretação sobre o caos, que, por sua vez, relaciona-se à possibilidade de um estado de exceção.

\footnotetext{
* Mestrando do Programa de Pós-Graduação em Direito da Universidade Federal de Minas Gerais (UFMG). Graduado em Direito pela Universidade Estadual Paulista "Júlio de Mesquita Filho" (UNESP). Bolsista CNPq-Brasil. E-mail: perinimilao@gmail.com ** Graduado em Direito, Mestre em Filosofia do Direito e Doutor em Direito e Justiça pela Faculdade de Direito da Universidade Federal de Minas Gerais (UFMG). Professor Adjunto de Filosofia do Direito e disciplinas afins na Faculdade de Direito da UFMG. Membro do Corpo Permanente do Programa de Pós-Graduação em Direito da UFMG. Professor Titular de Filosofia do Direito no curso de Graduação em Direito da FEAD (Belo Horizonte/MG). Diretor da Revista Brasileira de Estudos Políticos. E-mail: andityas@ufmg.br
} 
Palavras-chave: força. exceção. indivíduo. inimigo. Hans Kelsen. Carl Schmitt.

\begin{abstract}
Carl Schmitt has as one of his major theoretical opponent Hans Kelsen, which is mainly due to Kelsen's proposal to unlink politics of the legal science field, advocating a unitary conception of the Law and the State, identifying each other, unlike Schmitt who conceives a dualistic conception of the State and the Law, what in this case allows the suspension of the latter by the Sovereign in order to answer the "public interest", hypothesis heavily denied by Kelsen. Along with Rudolf Smend and Hermann Heller, Schmitt and Kelsen made up the so-called "weimarian quartet" in a period of "vacuum" between the two World Wars. Not surprisingly, the concept of strength exerts a central role in both the work of the master of the Vienna School, as the lawyer of the "exception", making thus the object of this article: to analyze and compare the matter of the violence and the issue of anomie as the founding of the State Law and the thought of these two great figures of the twentieth century. There is an essential difference between Schmitt and Kelsen when it concerns the extent of the strength as a foundational element of the legal or political order, this limit determined by the idea of anomie and the interpretation of the chaos, which relates to the possibility of a state of exception.
\end{abstract}

Keywords: strength. exception. individual. enemy. Hans Kelsen. Carl Schmitt.

\title{
INTRODUÇÃO
}

O título deste trabalho, especialmente as palavras "indivíduo" e "inimizade", não é apenas uma referência às bases metodológicas, políticas e conceituais dos autores em questão, a saber, Hans Kelsen e Carl Schmitt, mas antes de tudo, uma menção ao indivíduo Hans Kelsen e ao indivíduo Carl Schmitt e à relação de inimizade teórica entre eles, muito embora, frise-se, o conceito de inimigo em Carl Schmitt não faça referência à relação entre sujeitos, pautando sua aplicação no âmbito da comunidade e do conflito entre Estados.

Essa relação de "inimizade" é retratada principalmente devido ao intuito de Kelsen em desvincular a política do campo da ciência jurídica, defendendo uma concepção unitária de Direito e Estado, identificandoos, ao contrário de Schmitt que concebe uma visão dualista entre Estado e Direito, o que possibilitaria a suspensão do último pelo Soberano para atender ao chamado "interesse público", hipótese veementemente negada por Kelsen. Mas não só. As antinomias, aparentes ou não, entre esses dois autores, permeiam, além da Teoria do Estado e do Direito, outros campos conexos do saber, como a Teoria da Constituição, a Teoria da Democracia e a Filosofia do Conhecimento; na verdade, essa última, como não poderia deixar de ser, uma vez que estabelece o ponto de vista de cada autor, é a causa para a divergência nas demais. 
Desse modo, o método utilizado neste artigo "importa", mesmo que aplicado em âmbito diverso, o núcleo da metodologia schmittiana para o conhecimento do Político (mas não a sua Filosofia do Conhecimento), ou - como constata Renato Lessa em prefácio para o livro de Bernardo Ferreira, "O Risco do Político" -, opera a antinomia necessária para a cognição humana (FERREIRA, 2004, p. 19).

Assim, o estudo das oposições (e também das semelhanças) existentes no pensamento de Hans Kelsen e de Carl Schmitt revela-se essencial para a compreensão do que se pretende abordar e demonstrar neste trabalho. Mas, mais do que isso, estudar o conflito Kelsen Vs Schmitt é fundamental caso se queira entender a Filosofia e a Teoria do Estado e do Direito contemporâneas.

O presente artigo visa analisar a questão da violência e a problemática da anomia como fundantes do Direito e do Estado nas teorias desses dois polêmicos e importantes juristas do século XX. Isso será feito a partir da comparação da idéia de Norma Hipotética Fundamental, em Kelsen, com o conceito de Inimigo, em Schmitt, apontando suas semelhanças e diferenças metodológicas e epistemológicas. Com isso, tem-se como objetivo central demonstrar o papel que a força exerce no pensamento jurídico de Hans Kelsen e Carl Schmitt, refletindo não só nos desdobramentos práticos de suas teorias, mas principalmente, na formação das bases conceituais dessas.

Assim, pretende-se analisar a extensão que a idéia de força assume em cada autor e o conseqüente reflexo dessa concepção para o entendimento do caos e para a possibilidade ou não de um estado de exceção.

Para tanto, daremos atenção especial - em maior ou menor escala - ao pensamento desenvolvido nas obras "Teoria Pura do Direito" (1934/1960), "Essência e Valor da Democracia" (1920), "Deus e Estado" (1922-1923), “A Jurisdição Constitucional” (1928) e "Quem deve ser o guardião da Constituição" (1930-1931), de Hans Kelsen; "O Conceito do Político" (1927), "Teologia Política" (1922), "Teoria da Constituição" (1928) e “O Guardião da Constituição" (1929/1931), de Carl Schmitt.

Nesse contexto, abordaremos as opções metodológicas de Hans Kelsen e Carl Schmitt, respectivamente, a valorização do indivíduo e a importância da comunidade; bem como a filosofia do conhecimento por trás dessas escolhas, retratando um pensamento substancial em Schmitt e um pensamento funcional em Kelsen. 


\section{TEORIA DA JURISDIÇÃO CONSTITUCIONAL VS TEORIA DO PODER CONSTITUCIONAL ${ }^{1}$}

Juntamente com Rudolf Smend e Hermann Heller, Carl Schmitt e Hans Kelsen compunham o chamado "quarteto weimariano", em um período de "vácuo" entre as duas Guerras Mundiais. Nesse período, mais precisamente entre os anos de 1928 a 1933, ocorreu, na Alemanha, uma série de reuniões a respeito do Controle de Constitucionalidade e das funções da Corte Constitucional.

Kelsen, criador do modelo austríaco de controle de constitucionalidade e juiz da Suprema Corte da Áustria no período de 1921 até 1930, defendia, em oposição a Schmitt, uma ampliação das competências da Corte Constitucional alemã, que deveria, assim, abarcar também uma jurisdição constitucional nos moldes da experiência austríaca e não se limitar somente às tarefas de julgar o Presidente, as disputas entre os estados membros e entre os órgãos desses. De acordo com Kelsen,

A busca político-jurídica por garantias da Constituição, ou seja, por instituições através das quais seja controlada a constitucionalidade do comportamento de certos órgãos de Estado que lhe são diretamente subordinados, como o parlamento ou o governo, corresponde ao princípio, específico do Estado de direito, isto é, ao princípio da máxima legalidade da função estatal. (KELSEN, 2003, p. 239)

Esse conflito - que chamaremos aqui de "conflito de competência" - entre o jurista da exceção e o mestre da Escola de Viena é retratado na obra "O Guardião da Constituição", de Schmitt, e na obraresposta "Quem deve ser o Guardião da Constituição?”, de Kelsen. Para o primeiro, o Presidente do Reich é quem deveria exercer o controle constitucional, enquanto, para o segundo, o guarda da constituição

Este tópico de nosso artigo é baseado na aula ministrada pelo Professor Doutor Matthias Jestaedt - e traduzida consecutivamente do alemão para o português pelo Professor Doutor Eduardo Saad Diniz -, na cidade de Franca - SP, em 22/03/2012, na ocasião de Professor Visitante do Programa de Pós-Graduação em Direito da Universidade Estadual Paulista "Júlio de Mesquita Filho" - UNESP. 
deveria ser um juiz constitucional, defendendo, assim, o controle através de uma jurisdição.

Apoiando-se na teoria do pouvoir neutre, de Benjamin Constant, Schmitt argumenta:

El Presidente del Reich se halla en el centro de todo un sistema - construido sobre fundamentos plebiscitarios - de neutralidad e independencia respecto de los partidos políticos. A él está condicionada la ordenación política del actual Reich alemán, en la misma medida en que las tendencias del sistema pluralista dificultan y aun llegan a hacer imposible un normal funcionamiento del Estado legislativo. Antes de instituir un Tribunal para cuestiones y conflictos de alta política, como protector de la Constitución, antes de gravar y poner en peligro la Justicia con estas contaminaciones políticas, mejor seria recordar, en primer término, el contenido positivo de la Constitución de Weimar y de su sistema de preceptos. Según el contenido efectivo de la Constitución de Weimar existe ya un protector de la Constitución, a saber: el Presidente del Reich. (SCHMITT, 1998, p. 249)

No entanto, Kelsen rebate:

Através da imagem distorcida de uma sobrecarga da jurisdição, Schmitt procura inutilmente esquivar-se de admitir que não conseguiu comprovar sua tese do "chefe de Estado como guardião da Constituição" com o argumento de que ele estaria mais apto a protegê-la por possuir em maior medida que o tribunal a qualidade da independência e, portanto, da neutralidade. Antes, a própria fórmula com que Schmitt define a essência da "neutralidade", que seria pressuposto para a tarefa de guardião da Constituição, adapta-se justamente a um tribunal constitucional, militando diretamente contra o chefe de Estado. [...] De quem podemos dizer que se coloca como poder especial neutro "ao lado dos outros poderes": um tribunal destinado a nada mais que exercer um controle constitucional ou o chefe de Estado? É desse tribunal ou do chefe de Estado que devemos dizer que - se chamado a exercer a função de guardião da Constituição - recebe essa função 


\begin{abstract}
"adicionalmente", adquirindo destarte uma "preponderância" sobre os outros poderes instituídos pela Constituição, na medida em que assim "poderia, ele mesmo, esquivar-se do controle"? Nem mesmo a ideologia de Benjamin Constant do pouvoir neutre do monarca poderia obscurecer tanto essa interrogação a ponto de tornar a resposta seriamente duvidosa. (KELSEN, 2003, p. 285286)
\end{abstract}

Essas diferentes conclusões sobre quem deve exercer o controle de constitucionalidade tem como embasamento teórico outras duas divergências entre Kelsen e Schmitt: o "conflito de competência" é, na verdade, reflexo do que denominaremos "conflito constitucional", que, por sua vez, desdobra-se em um "conflito de aplicação".

Os conflitos "constitucional" e "de aplicação", além de presentes nos trabalhos citados acima, ganham densidade também com as obras "Teoria da Constituição" e "A Jurisdição Constitucional". Nesse sentido, veremos, a seguir, como tais antinomias se desenvolvem.

Carl Schmitt estabelece uma diferença entre Constituição e Leis Constitucionais, afirmando que a primeira não se encontra em um campo normativo, como acontece com as segundas. A Constituição é colocada, desse modo, em um campo singular, que não é o do ordenamento jurídico, mas sim o da Política, e como tal, o do Poder. Já em Kelsen não há essa distinção, as leis constitucionais são relativizadas e a Constituição, em um sentido jurídico-positivo, é entendida como uma norma posta e pertencente ao ordenamento.

Por esses motivos, é que dizemos que em Schmitt há uma Teoria do Poder Constitucional, enquanto em Kelsen há uma Teoria da Jurisdição Constitucional. Essas teorias não são apenas opostas, mas se negam reciprocamente, repercutindo, desse modo, no entendimento de quem deve ser o guarda da constituição.

É justamente por não incluir a Constituição dentro de um campo exclusivamente normativo, alocando essa em um âmbito político, que Schmitt irá afirmar a impossibilidade do controle constitucional ser exercido por um juiz, devendo ser feito pelo Presidente do Reich, o detentor da decisão política. Para o autor, "[...] es improcedente atribuir a la Justicia ciertas funciones que rebasan el ámbito de una subsunción real, es decir, que traspasan las fronteras establecidas por la sujeción a normas de contenido preciso." (SCHMITT, 1998, p. 97). 
Essa escolha metodológica, que nada mais é do que um reflexo da filosofia do conhecimento adotada pelo autor, também repercutirá no chamado "conflito de aplicação", uma vez que Schmitt considera o juiz como apolítico e, consequentemente, impossibilitado de criar Direito, exercendo somente uma função lógico-dedutiva, o que demonstraria a insuficiência do âmbito jurídico para o controle de constitucionalidade, dotado, como visto, de um aspecto político: "La independencia judicial es solamente el otro aspecto de la sujeción del juez a las leyes, y, por esta razón, es apolítica." (SCHMITT, 1998, p. 248). Nesse sentido: "La independencia de los jueces no tiene, empero, en el Estado actual, la misión de crear un titular para la generación auténtica de la voluntad del Estado, sino la de delimitar y asegurar, dentro de un sistema estatal ordenado, una esfera de la Justicia sujeta a la ley." (SCHMITT, 1998, p. 245).

Mais uma vez, o pensamento schmittiano demonstra-se divergente com o argumentado por Kelsen, que, apesar de concordar com o fato de o juiz ser apolítico, defende a possibilidade de criação do Direito pelo juiz, pois o ato de aplicação da lei comporta uma parte cognitiva e outra volitiva que se desenvolvem dentro de um esquema hermenêutico de "molduras".

Toda essa discussão sobre o controle de constitucionalidade e as antinomias por nós analisadas sob a forma de "conflitos" (de competência, constitucional e de aplicação) estão inseridas em e tem suas conclusões advindas de uma Teoria da Democracia. Apesar das diferentes respostas a que chegam Schmitt e Kelsen sobre o guardião da Constituição, ambos colocam suas teorias em defesa da democracia, muito embora, como não poderia deixar de ser, tenham interpretações diversas sobre como se dá a realização de tal forma de governo.

Enquanto Kelsen, baseado na idéia de liberdade e em uma valorização do indivíduo, consequentemente, expressando um pluralismo e a preocupação da permanência de tal pluralismo, defende a idéia de uma democracia realizada - não como um fim ideal, mas como um meio prático - através de um compromisso, que se dá no Parlamento, entre as maiorias e minorias, contemplando, assim, de certa forma, as diversas vontades existentes; Schmitt, com base na idéia de igualdade tem na comunidade o seu referencial democrático, que só pode ser expresso com a aclamação de um Presidente que, dotado de um caráter plebiscitário, coloca-se como representante do povo e por isso mesmo, deve ser o guardião da Constituição, já que: 
La Constitución vigente en el Reich afirma la idea democrática de la unidad homogénea e indivisible de todo el pueblo alemán, que, en virtud de su poder constituyente, se ha dado a sí mismo esta Constitución mediante una decisión política positiva, es decir, mediante un acto unilateral. Por esta razón, todas aquellas interpretaciones y aplicaciones de la Constitución de Weimar que pretenden ver en ella un contrato, un compromiso o algo semejante, deben rechazarse solemnemente por vulnerar el espíritu de la Constitución. (SCHMITT, 1998, p. 113).

Assim, a Constituição, em Schmitt, não se coloca apenas em um campo singular, não-normativo e essencialmente político, mas, principalmente, detém uma essência ontológica, uma vez que surge do povo, conceito que, como veremos, para Schmitt, nada mais é do que um conceito teológico secularizado. A idéia de povo em Schmitt adquire um caráter substancial e não funcional como o adotado por Kelsen. Desse modo, o "conflito constitucional" entre esses dois antagonistas do século $\mathrm{XX}$ e, consequentemente, os conflitos "de competência" e "de aplicação", fundamentados pelo primeiro, são reflexos de um "conflito de conhecimento".

\section{NORMA HIPOTÉTICA FUNDAMENTAL VS CONCEITO DE INIMIGO}

Antes de adentrarmos a discussão do "conflito de conhecimento" e sua correlação com o objetivo deste trabalho, é essencial que façamos uma análise dos conceitos-chave das teorias de Hans Kelsen e Carl Schmitt, respectivamente, a norma hipotética fundamental e o conceito de inimigo.

A idéia schmittiana de inimigo - apesar da estranheza inicial que a afirmação a seguir possa causar - assemelha-se à norma hipotética fundamental kelseniana. Essa semelhança ocorre quanto à função que esses dois conceitos exercem na teoria defendida por cada um dos autores, pois a norma hipotética fundamental coloca-se como um pressuposto lógico-transcendental, baseando-se na filosofia de Kant e expressando uma resposta à pergunta de "como é possível conhecer?", e a inimizade, conforme expõe Bernardo Ferreira em sua obra "O Risco do Político", "tem um papel estrutural, ela é um ponto de vista 
epistemológico que, como tal, é interno ao processo de conhecimento." (FERREIRA, 2004, p. 48).

Veremos, a seguir, a concepção desses conceitos no pensamento de seus devidos autores.

\subsection{Norma Hipotética Fundamental}

Considerando o normativismo kelseniano que defende a fundamentação de um dever-ser apenas em outro dever-ser (e não em um ser - apesar de não desvincular de modo absoluto essas duas esferas), para possibilitar um conhecimento científico do Direito, Kelsen cria a figura da Norma Hipotética Fundamental (Grundnorm), de "[...] natureza não-positiva e essencialmente epistemológica [...], pressuposta pelo pensamento jurídico" (MATOS, 2005, p. 69) e que "[...] só pode ser expressa em termos condicionais: se reconhecemos uma ordem jurídica como válida e globalmente eficaz, necessariamente devemos pressupor uma norma fundamental que lhe confira fundamento." (MATOS, 2005, p. 69).

Dessa forma,

[...] assim como Kant havia se perguntado como era possível conhecer, referindo-se às ciências naturais, Kelsen se pergunta como é possível conhecer o fenômeno social chamado direito. Para tanto, é preciso pensar - à maneira kantiana - um pressuposto lógico-transcendental capaz de fundamentar toda a ordem jurídica. Surge, então, a norma fundamental (Grundnorm), que tem função eminentemente epistemológica na teoria kelseniana, razão suficiente para afirmar que o normativismo de Kelsen não é um mero logicismo no qual as normas inferiores são obtidas por meio de um processo hipotético-dedutivo que tem como premissa maior a norma fundamental. (MATOS, 2005, p. 64)

Segundo Kelsen, a função da norma hipotética é

[...] fundamentar a validade objetiva de uma ordem jurídica positiva, isto é, das normas, postas através de atos de vontade humanos, de uma ordem coercitiva globalmente eficaz, quer dizer: interpretar o sentido subjetivo destes atos como seu sentido objetivo. (KELSEN, 1998, p. 225-226) 
Desse modo, “[...] a norma fundamental limita-se a delegar numa autoridade legisladora, quer dizer, a fixar uma regra em conformidade com a qual devem ser criadas as normas deste sistema." (KELSEN, 1998, p. 219).

A pressuposição de uma norma como norma fundamental está, com isso, intimamente ligada à escolha de um ordenamento jurídico em específico, pois, como fundamento de validade deste, a norma hipotética fundamental estabelece-se como uma regra que dita como devem ser criadas as normas gerais e individuais do ordenamento, ao mesmo tempo em que determina qual será o ordenamento e permite a existência desse, uma vez que lhe confere validade e promove a unidade de uma pluralidade de normas.

Com isso, conforme expõe Kelsen, a norma hipotética fundamental

[...] é o ponto de partida de um processo: do processo da criação do Direito positivo. Ela própria não é uma norma posta, posta pelo costume ou pelo ato de um órgão jurídico, não é uma norma positiva, mas uma norma pressuposta, na medida em que a instância constituinte é considerada como a mais elevada autoridade e por isso não pode ser havida como recebendo o poder constituinte através de uma outra norma, posta por uma autoridade superior. (KELSEN, 1998, p. 222)

Assim,

Uma norma pertence a um ordenamento que se apóia numa tal norma fundamental porque é criada pela forma determinada através dessa norma fundamental - e não porque tem um determinado conteúdo. A norma fundamental apenas fornece o fundamento de validade e já não também o conteúdo das normas que formam este sistema. Esse conteúdo apenas pode ser determinado através de atos pelos quais a autoridade a quem a norma fundamental confere competência e as outras autoridades que, por sua vez, recebem daquela a sua competência, estabelecem as normas positivas deste sistema. (KELSEN, 1998, p. 219-220)

Afirma-se, sobretudo, que "O princípio segundo o qual se opera a fundamentação da validade das normas deste sistema é um princípio dinâmico"(KELSEN, 1998, p. 219), pois 
O tipo dinâmico é caracterizado pelo fato de a norma fundamental pressuposta não ter por conteúdo senão a instituição de um fato produtor de normas, a atribuição de poder a uma autoridade legisladora ou - o que significa o mesmo - uma regra que determina como devem ser criadas as normas gerais e individuais do ordenamento fundado sobre esta norma fundamental. (KELSEN, 1998, p. 219)

\subsection{Inimizade}

A inimizade, em Schmitt, retratada principalmente em sua obra "O Conceito do Político", é desenvolvida pelo autor a partir da díade amigo/inimigo que se insere em um contexto de relacionamentos entre Estados. Assim, o conceito de inimigo está intimamente relacionado a uma comunidade e não a indivíduos ou grupo de indivíduos em particular, constituindo justamente a essência do povo, que passa a se conhecer a partir do outro antagônico, na verdade, que só passa a se conhecer quando percebe a ameaça existencial provocada por esse outro, elevado então ao status de inimigo. Nesse sentido:

Um povo politicamente existente não pode renunciar, quando for o caso, a diferenciar amigo e inimigo com uma determinação por sua conta e risco. [...] Se deixa de existir esta diferenciação, deixa de existir então a vida política em geral. Um povo politicamente existente não é a de maneira nenhuma livre para escapar, através de proclamações juradas, desta diferenciação prenhe de destino. (SCHMITT, 1992, p. 77)

Dessa forma, como bem expõe Bernardo Ferreira,

Para Schmitt, o antagonismo entre amigo e inimigo possui um caráter público. Trata-se de uma contraposição que opõe coletividades e não adversários privados. O inimigo político é em primeiro lugar um inimigo público, e a hostilidade em relação a ele não precisa se manifestar sob a forma do ódio privado. Sendo assim, as motivações do conflito político devem ser pensadas em termos da sua natureza pública, ou seja, as razões da luta política devem ser buscadas naquilo que opõe os grupos humanos como coletividades. O político, portanto, "pode extrair a sua força das mais diferentes esferas da vida humana, de contraposições religiosas econômicas, morais e outras" 
(BP, 38). No entanto, apesar de diferentes campos da experiência humana poderem assumir um significado especificamente político, Carl Schmitt insiste em que a dissociação amigo-inimigo não deriva dos conteúdos das contraposições das diferentes esferas da existência. [...] O político, portanto, não possui uma substância própria, manifestando-se como uma forma específica de comportamento. Uma forma de comportamento em que os homens se dividiriam em amigos e inimigos, tendo em vista a possibilidade-limite da guerra. (FERREIRA, 2004, p. 41).

O conceito de inimigo coloca-se, então, como o núcleo metodológico schmittiano para o conhecimento do Político, uma vez que operacionaliza as antinomias necessárias para tanto e também para o autoconhecimento da comunidade e sua conseqüiente formação enquanto Estado:

[...] o inimigo não é o adversário ocasional com quem sou levado a me confrontar na formulação das minhas idéias. A inimizade, dada a natureza-limite do conflito político, é uma condição da elaboração do pensamento político, da sua construção polêmica a partir de um antagonista. Vale a pena insistir nesse ponto: Schmitt pensa contra um adversário, mas também através dele. Sendo assim, o inimigo não é apenas alguém, por assim dizer, situado fora, uma realidade exterior com a qual o pensamento se defronta. (FERREIRA, 2004, p. 48)

\subsection{Horizonte de possibilidade de violência}

Diante da exposição sobre as funções da norma hipotética fundamental e da idéia de inimigo, é possível desenvolver um pouco mais as semelhanças operacionais entre esses dois conceitos.

A norma hipotética fundamental é o que permite classificar, na teoria kelseniana, determinados comandos como jurídicos, diferenciandoos dos demais comandos e ordens, dotando-os de dever-ser objetivo. Nesse sentido, de forma análoga, o inimigo qualifica quais conflitos podem ser entendidos como conflitos políticos dentre uma série de divergências e oposições. Dessa maneira, na medida em que a norma hipotética fundamental exerce apenas um fundamento de validade e não um conteúdo ou teor de validade, inserindo-se assim em um princípio dinâmico de derivação normativa e não em um princípio estático, o que 
permite afirmar que qualquer conteúdo pode vir a ser direito; o conceito de inimigo torna possível que qualquer tipo de conflito, divergência ou oposição, seja ele étnico, religioso, econômico, entre outros, possa vir a ser político.

No entanto, a semelhança que nos interessa para o presente trabalho é aquela que se insere especificamente em uma epistemologia, expressando um horizonte de possibilidade de violência.

Da mesma forma que, em um ponto de vista científico, a norma hipotética fundamental permite constatar o Direito, o conceito de inimigo permite reconhecer o Político; e a força exerce uma influência determinante para tanto.

Conforme analisa Bernardo Ferreira,

A guerra seria, para empregar um termo caro a Schmitt, o "caso crítico" (Ernstfall) em função do qual o antagonismo entre os grupos humanos atingiria o ponto da sua distinção entre amigos e inimigos. A política, longe de se confundir com a guerra, encontraria nela uma possibilidade última e real que condicionaria o comportamento político dos homens. (FERREIRA, 2004, p. 37-38)

No entendimento de Schmitt, a distinção amigo/inimigo ocorre, ao menos em última escala, a partir da guerra; o direito de agressão física e de morte ao outro, ao mesmo tempo em que declara o inimigo, estabelece a comunidade e exprime o Político. Já em Hans Kelsen, a força está relacionada à norma hipotética fundamental uma vez que é inerente ao princípio da efetividade, que se aplica à manutenção de um status quo ou à formação de um novo Poder Constituinte Originário por meio da revolução.

Para Kelsen, o Direito diferencia-se das demais ordens sociais justamente pela estatuição de atos coativos, que tem taxativamente determinada pela ordem jurídica as suas condições de aplicação, caracterizando, assim, um monopólio da coação.

Quanto a isso, Hans Kelsen bem observa que:

Como ordem coativa, o Direito distingue-se de outras ordens sociais. O momento coação, isto é, a circunstância de que o ato estatuído pela ordem como conseqüência de uma situação de fato considerada socialmente prejudicial deve ser executado mesmo contra a vontade da pessoa 
atingida e - em caso de resistência - mediante o emprego da força física, é o critério decisivo. (KELSEN, 1998, p. 37)

No entanto, apesar de Kelsen compreender o Direito como caracterizado pela força, esse elemento por si só não basta para a concepção de um ordenamento jurídico, pois expressa somente um dever-ser subjetivo, não suficiente para distinguir a vontade do Estado daquela emanada por um bando de salteadores. É nesse contexto que, criticando as correntes Imperativistas do positivismo jurídico do século XIX, que baseavam a validade do Direito unicamente na força de um Soberano, tendo Bentham e Austin como principais autores, que Kelsen irá introduzir a necessidade de um dever-ser objetivo, advindo de um esquema escalonado de normas válidas e que trará a necessidade das normas serem vinculativas e, por isso mesmo, a eficácia será entendida como condição de validade, apesar de não se confundir com aquilo que condiciona.

Considerando as normas jurídicas isoladamente, a validade dessas é o que vincula os indivíduos a se comportarem de acordo com o prescrito. Porém, esta validade é advinda, em última instância, da norma hipotética fundamental que, para ser assim pressuposta, diante da eficácia como condição de validade, depende da obediência de uma coletividade de indivíduos, que "[...] não deve se basear exclusivamente na força, mas em sua adesão a um poder legitimado pelo sistema de regras previamente estabelecidas" (BILLIER; MARYIOLI, 2005, p. 209).

É nesse contexto que se insere o princípio da legitimidade, limitado pelo princípio da efetividade, expressando, assim, o mínimo de força e o mínimo de eficácia necessários para a caracterização do Direito em termos kelsenianos. Kelsen explica essa relação através de um processo revolucionário interpretado como um processo produtor de Direito:

Uma revolução no sentido amplo da palavra, compreendendo também o golpe de Estado, é toda modificação ilegítima da Constituição, isto é, toda modificação da Constituição, ou a sua substituição por uma outra, não operadas segundo as determinações da mesma Constituição. Dum ponto de vista jurídico, é indiferente que esta modificação da situação jurídica seja produzida através de um emprego da força dirigida contra o governo legítimo ou pelos próprios membros deste governo, através de um movimento de massas populares ou de um pequeno grupo 
de indivíduos. Decisivo é o fato de a Constituição vigente ser modificada ou completamente substituída por uma nova Constituição através de processos não previstos pela Constituição até ali vigente. (KELSEN, 1998, p. 233)

Desse modo,

As leis ditadas sob a antiga Constituição e que não sejam recebidas já não são consideradas válidas, os órgãos instituídos de acordo com a antiga Constituição já não são considerados competentes. Se a revolução não fosse bemsucedida, quer dizer, se a Constituição revolucionária - que não veio à existência de acordo com a antiga Constituição não se tivesse tornado eficaz, se os órgãos por ela previstos não tivessem ditado quaisquer leis que fossem de fato aplicadas pelos órgãos previstos nestas leis, mas se, pelo contrário, a antiga Constituição tivesse permanecido eficaz, não haveria qualquer motivo para pressupor uma nova norma fundamental no lugar da antiga. (KELSEN, 1998, p. 235)

Depreende-se que a norma hipotética fundamental necessita de um mínimo de força para ser pressuposta, impondo assim um mínimo de eficácia caracterizador do Direito. No entanto, essa eficácia genérica do ordenamento jurídico não pode se basear majoritariamente na força de um Poder Constituinte Originário, pois, se assim fosse, em nada se diferenciaria das concepções Imperativistas, carecendo de dever-ser objetivo (MILÃO, 2011, passim).

Por outro lado, o conceito de inimigo encontra o ápice de sua expressão na maximização última da força, já que, nas palavras de Bernardo Ferreira citando Carl Schmitt, "A guerra é tão somente 'a mais extrema realização da inimizade' e, como tal, o seu 'pressuposto último"” (FERREIRA, 2004, p. 40). Nesse sentido,

Por se tratar de uma situação em que está dada a possibilidade de provocar e sofrer a morte física, a guerra constitui a "mais extrema possibilidade" (BP, 35), o horizonte de referência último da contraposição entre amigos e inimigos, em razão do qual "a vida dos homens adquire uma tensão especificamente política" (BP, 35). Portanto, os antagonismos políticos remetem ao "caso de guerra" porque é neste "caso-limite" (PT, 13) em que se 
Assim, apesar de tanto Kelsen como Schmitt fundarem seus conceitos em um horizonte de possibilidade de violência, há uma diferença essencial entre Schmitt e Kelsen quanto à extensão do elemento força como fundante do ordenamento jurídico ou da ordem política, questão essa que veremos a seguir.

\section{SUBSTÂNCIA VS FUNÇÃO [CONCLUSÕES]}

O limite (ou ausência de limite) conferido à força no pensamento de Hans Kelsen e Carl Schmitt é determinado pela idéia de anomia e pela interpretação sobre o caos, que, por sua vez, relaciona-se à possibilidade de um estado de exceção. Nesse contexto, em Schmitt, o uso exacerbado da força visa a salvar o ordenamento jurídico vigente e/ou o Estado, enquanto em Kelsen, o uso excessivo dessa força expressa somente a já não existência do Direito e, consequentemente, do Estado.

A noção de dever-ser objetivo presente na teoria kelseniana, tendo a norma hipotética fundamental como pilar, ao limitar o uso da força, livrando a eficácia de se constituir exclusivamente sob esse elemento, condiciona, ao menos indiretamente, a validade do ordenamento jurídico a uma valorização do indivíduo, expressada pela idéia de autonomia moral, refletindo na obediência ou não das normas de conduta, ou melhor, na possibilidade de uma anomia do ponto de vista do indivíduo, fato esse que confere destaque à eficácia das normas secundárias, que se dirigem diretamente à população, contrapondo-se à eficácia das normas primárias, constituída a partir da aplicação de uma sanção, logo, a partir do uso da força (MILÃO, 2011, passim). Assim, há uma relação inversamente proporcional entre a eficácia das normas primárias e a eficácia das normas secundárias, sendo que a primeira não pode preponderar sobre a segunda, já que, caso isso ocorra, a validade do ordenamento jurídico estaria reduzida a atos de força, algo inaceitável para Kelsen (MILÃO, 2011, passim).

Desse modo, em uma análise do âmbito interno (nacional), a norma hipotética fundamental não mais é pressuposta quando há a maximização última da força (MILÃO, 2011, passim), maximização entendida aqui (âmbito interno), como situação de exceção. 
Isso influencia diretamente na diferença de interpretação que cada um dos dois autores faz sobre o caos, compreendido como agressão ao status quo e ineficácia das normas jurídicas. Enquanto Carl Schmitt combaterá o caos com o estado de exceção para salvar a comunidade, utilizando a força para tanto; Hans Kelsen verá no caos, retratado pela anomia, a expressão da autonomia moral, entendida positivamente como liberdade individual, uma vez que o jurista austríaco "concebe a autonomia moral de modo que seja o norte de cada ser humano. Somos os únicos responsáveis pelos nossos destinos. O peso dos nossos erros e acertos não pode ser anulado, minorado, transferido, trocado, negociado ou esquecido" (MATOS, 2005, p. 281-282).

Assim, na verdade, o tratamento da força tanto em Kelsen, como em Schmitt, é uma expressão das opções metodológicas desses autores, respectivamente: a valorização do indivíduo e a importância da comunidade.

Há uma extensão menor do elemento força na teoria kelseniana, pois o caos é interpretado como expressão da autonomia moral, refletindo a liberdade do indivíduo. Já em Schmitt, há uma extensão maior da força porque o caos é visto como agressão à comunidade, talvez por retratar justamente um caráter liberal.

Essas opções metodológicas, no entanto, refletem o "conflito de conhecimento" existente entre Kelsen e Schmitt, conforme já adiantado, uma vez que Kelsen negará a valorização da comunidade (ou do povo) e a luta por sua permanência, desfazendo a lógica da necessidade de um estado de exceção, justamente por não considerar que a comunidade esteja inserida em um campo do ser, em um campo ontológico, razão pela qual não coloca a idéia de povo como fundamento metodológico de sua teoria, como também não aceita a idéia de uma Constituição desvinculada do campo do dever-ser. O pensamento kelseniano é pautado por um caráter funcional e não substancial, eliminando qualquer tipo de dualismos e de ordens pré-estabelecidas ou simplesmente dadas.

Para Kelsen,

Como comunidade social, o Estado - de acordo com a teoria tradicional do Estado - compõe-se de três elementos: a população, o território e o poder, que é exercido por um governo estadual independente. Todos estes três elementos só podem ser definidos juridicamente, isto é, eles apenas podem ser apreendidos como vigência e domínio de vigência (validade) de uma ordem jurídica. [...] A 
população é constituída pelos indivíduos que pertencem a um Estado. Se se pergunta por que é que um indivíduo, conjuntamente com outros indivíduos, pertence a um determinado Estado, não poderemos encontrar outro critério para a resposta que não seja o de que ele está, conjuntamente com os outros, submetido a uma determinada ordem coerciva relativamente centralizada. Todas as tentativas para encontrar um outro vínculo que reúna, transforme numa unidade, indivíduos de línguas, raças, religiões e acepções de vida possivelmente diferentes, separados por oposições de classe e numerosos outros conflitos de interesses, falham necessariamente. [...] A unidade dos indivíduos que formam a população de um Estado em nada mais pode ver-se do que no fato de que uma e a mesma ordem jurídica vigora para estes indivíduos, de que a sua conduta é regulada por uma e a mesma ordem jurídica. A população do Estado é o domínio pessoal de vigência da ordem jurídica estadual. (KELSEN, 1998, p. 318-319)

Já a Filosofia do Conhecimento do jurista da exceção é retratada em sua obra "Teologia Política", na qual considera que os conceitos da moderna doutrina do Estado são conceitos teológicos secularizados. Desse modo, o conceito de povo, de forma análoga à concepção de um Deus soberano, detém uma essência ontológica, o que permite conceber a Constituição em um plano singular, desvinculada de um dever-ser.

Nesse sentido, Hans Lindahl analisa que "La observación de Schmitt, <<sólo algo concretamente existente... puede ser soberano〉>, incurre en el category mistake característico del substancialismo ontológico: conceptualiza la soberanía como la propiedad de una substancia" (LINDAHL, 1996, p. 64).

E o autor continua:

Una de las contribuciones fundamentales de Hans Kelsen a la filosofía política de nuestro siglo ha sido explicitar la relación entre estado y derecho propia de la modernidad. Ello no sorprende, ya que su teoría pura del derecho puede ser comprendida como el esfuerzo sistemático de extraer las consecuencias jurídicas de la prioridad moderna de las funciones sobre las substancias. En particular, critica exhaustivamente las doctrinas del estado que, según muestra, hacen del estado una substancia. $<<$ Conforme a la visión predominante, el estado es visto como un ser existente distinto al derecho, que se ha independizado de 
éste >> (18). De esta manera, la doctrina tradicional de la relación entre estado y derecho incurre en el dualismo del substancialismo ontológico: por una parte, un orden real autónomo, dado inmediatamente - el estado -; por la otra, un orden conceptual (normativo) que reproduce al primero - el derecho -. Una visión dualista de la relación entre estado y derecho presupone, pues, que el pensamiento representa el ser. En otras palabras, el dualismo da por descontada la prioridad de la presencia frente a la representación. Contra este presupuesto, Kelsen hace valer la prioridad de la función. (LINDAHL, 1986, p. 65)

Assim, diante de todo o exposto, depreende-se, de modo claro, como as filosofias do conhecimento adotadas por Kelsen e por Schmitt interferem na concepção de suas teorias do Direito, do Estado, da Constituição, da Democracia e da Aplicação/Interpretação, bem como na opção metodológica que as embasa.

O "conflito de conhecimento" revela-se, com isso, a linha que determina o horizonte de possibilidade de violência no pensamento jurídico de Hans Kelsen e de Carl Schmitt, fundando as antinomias existentes entre esses dois autores e atribuindo maior ou menor profundidade e dimensão ao papel da força.

\section{REFERÊNCIAS}

\section{BILLIER, Jean-Cassien; MARYIOLI, Aglaé. História da filosofia do} direito. Tradução de Maurício de Andrade. Revisão Científica de Marcelo Solon. São Paulo: Manole, 2005.

FERREIRA, Bernardo. O risco do político: crítica ao liberalismo e teoria política no pensamento de Carl Schmitt. Belo Horizonte: Editora UFMG; Rio de Janeiro: IUPERJ, 2004.

KELSEN, Hans. A democracia. Tradução de Ivone Castilho Benedetti. 2. ed. São Paulo: Martins Fontes, 2000.

. Deus e Estado. In: MATOS, Andityas Soares de Moura Costa; SANTOS NETO, Arnaldo Bastos (coords.). Contra o absoluto: perspectivas críticas, políticas e filosóficas da obra de Hans Kelsen. Curitiba: Juruá, 2011. p. 37-53. 
. Jurisdiçãao constitucional. Tradução de Alexandre Krug. São Paulo: Martins Fontes, 2003.

. Teoria pura do direito. Tradução de João Baptista Machado. 6. ed. São Paulo: Martins Fontes, 1998.

LINDAHL, Hans. El pueblo soberano: el régimen simbólico del poder político en la democracia. Revista de Estudios Políticos (Nueva Época), n. 94, p. 47-72, 1996.

MATOS, Andityas Soares de Moura Costa. Filosofia do direito e justiça na obra de Hans Kelsen. 2. ed. Belo Horizonte: Del Rey, 2005.

MILÃO, Diego Antonio Perini. Direito: força e anomia. 2011. $99 \mathrm{f}$. Trabalho de Conclusão de Curso (Bacharelado em Direito) - Faculdade de Ciências Humanas e Sociais, Universidade Estadual Paulista "Júlio de Mesquita Filho", Franca, 2011.

SCHMITT, Carl. La defensa de la Constitución. Tradução de Manuel Sanchez Sarto. 2. ed Madrid: Tecnos, 1998.

. O conceito do político. Tradução de Álvaro L. M. Valls. Petrópolis: Vozes, 1992.

. Teologia política. Tradução de Elisete Antoniuk. Belo Horizonte: Del Rey, 2006.

Teoria de la Constitución. Tradução de Francisco Ayala.

Madrid: Alianza Editorial, 1982. 